\title{
Comparative toxicity assessment between generic salbutamol sulphate inhaler containing hydrofluoroalkane and Ventolin Evohaler
}

\author{
Suvas C. Singho Roy ${ }^{1}$, M. A. Jalil ${ }^{2}$, Nigar Sultana Tithi ${ }^{1}$, Sajal K. Saha ${ }^{3}$, Sheikh Zahir Raihan ${ }^{3}$, \\ Utpal K. Chanda ${ }^{4}$, Chanchal K. Ghosh ${ }^{5}$, Sitesh C. Bachar ${ }^{1 \#}$ \\ ${ }^{1}$ Department of Pharmaceutical Technology, Faculty of Pharmacy, University of Dhaka, Dhaka, Bangladesh; \\ \#Corresponding Author: siteshbachar@yahoo.com, bacharsc63@gmail.com \\ ${ }^{2}$ Department of Statistics, Biostatistics and Informatics, Faculty of Science, University of Dhaka, Dhaka, Bangladesh \\ ${ }^{3}$ Department of Clinical Pharmacy and Pharmacology, Faculty of Pharmacy, University of Dhaka, Dhaka, Bangladesh \\ ${ }^{4}$ Department of Pediatrics, Khulna Medical College and Hospital, Khulna, Bangladesh \\ ${ }^{5}$ Department of Gastroenterology, Bangabandhu Sheikh Mujib Medical University, Dhaka, Bangladesh
}

Received 9 April 2013; revised 12 May 2013; accepted 20 May 2013

Copyright (C) 2013 Suvas C. Singho Roy et al. This is an open access article distributed under the Creative Commons Attribution License, which permits unrestricted use, distribution, and reproduction in any medium, provided the original work is properly cited.

\section{ABSTRACT}

Salbutamol is a short-acting $\beta_{2}$-adrenergic receptor agonist used for the relief of bronchospasm such as asthma and chronic obstructive pulmonary disease (COPD). It is mostly taken through an inhaler device. The comparative toxicity assessment between two salbutamol sulfate preparations containing hydrofluoroalkane (HFA) metered dose inhalers with $100 \mu \mathrm{g}$ per puff was evaluated in selected patients with asthma and COPD after prescribing. An open label, non-randomized, non-interventional observational study was designed. A large cohort of patients with asthma or related respiratory disorder of the general population from Dhaka and Chittagong of Bangladesh were recruited and treated with prescribed generic preparation Azmasol inhaler and brand preparation Ventolin Evohaler. Total 508 patients with asthma and minor obstructive airway disease were selected by the general medical practitioners in Bangladesh those who visited out patient consultation center in hospitals and physicians' chambers and reported any adverse side effects of inhaled medications. There were no significant differences between the metered dose generic preparation Azmasol inhaler and Ventolon Evohaler

\footnotetext{
*Conflict of Interest: The other authors were members of the steering committee. There is no conflict of interest among the members.

Funding: This study was funded by the internal source of department of Pharmaceutical Technology, Faculty of Pharmacy, University of Dhaka, Dhaka-1000 Bangladesh.
}

among the patients treated with the medicines in asthma and related respiratory diseases in terms of adverse effects like immune system problem, dizziness, tremor, headache, nervousness, diarrhea, nausea, vomiting, heartburn, palpitation, skin rash, hypertension and taste feeling. It is concluded that Azmasol Inhaler, the generic salbutamol sulphate metered dose preparation containing HFA was as safe as the Ventolin Evohaler, a salbutamol sulfate brand preparation containing HFA when given to the patients in primary care after their physicians' visits. Both the preparations have shown the similar safety profiles after regular use.

Keywords: Salbutamol Sulphate; Hydrofluoroalkane; Toxicity Assessment; Adverse Drug Reaction; Asthma; Ventolin Evohaler

\section{INTRODUCTION}

Pharmaceutical drugs are mostly synthetic products made from chemicals. They are meant to improve the health and well-being of patients by helping to prevent and treat disease, reduce pain and suffering, and extend and save lives. The drug regulatory authority of the respective country is responsible to regulate the safety, efficacy, and quality of all pharmaceutical drugs for use by human before and after the products enter into market. This department does this through a combination of scientific review, monitoring, compliance, and enforcement activities. In Bangladesh, the Directorate General of Drug 
Administration (DGDA) follows almost the same procedure for safety and efficacy of the marketed products. It aims to ensure that the public has timely access to safe and effective pharmaceutical drugs and those who need to know of safety concerns are informed. They also monitor the safety of marketed drugs by collecting, analyzing, and assessing domestic adverse drug reaction reports that are submitted by the pharmaceutical industry, health professionals, and consumers as well.

The necessity to measure the safety of new medicines in large populations of patients is well established [1], when only a good number of patients are recruited into clinical trial programmes before a new drug is marketed [2]. It is only then that a comprehensive assessment of its safety can be made. A post-marketing surveillance is conducted in broadly based clinical settings contributes to the evaluation of drug safety. Controlled trials had shown that metered dose salbutamol inhalers using hydrofluoroalkane were comparable in terms of efficacy and safety to existing salbutamol inhalers using chlorofluorocarbon as the propellant [3-7]. Accordingly the post-market surveillance strategy ensures the benefits of using a drug without any risk. It fulfills the responsibility by gathering and assessing safety information [8]. The present study is designed to evaluate the safety assessment of Azmasol, a salbutamol sulfate pressurized, metered dose inhaler containing hydrofluoroalkane (HFA) prescribed to the patients in primary care by comparing it with Ventolin Evohaler using hydrofluoroalkane as propellant.

\section{MATERIALS AND METHODS}

An adverse drug reaction report form was prepared and filed up getting or extracting information from the patients' medical records or notes in the prescriptions written by the physicians. The general practitioners of different parts of Bangladesh were invited to participate in the study through a letter.

An independent steering committee was formed headed by the principal investigator. The committee's responsibilities was approving the study design, monitoring the progress, and reviewing reports of adverse events.

\section{STUDY DESIGN}

The method was followed as that of Ayers et al. [9] in an open label, non-randomized, non-interventional observational study. It was designed with a goal of recruiting rapidly a large cohort of patients' representative with asthma or related respiratory disorder of the general population from Dhaka and Chittagong of Bangladesh being treated with prescribed Azmasol inhaler $100 \mu \mathrm{g}$ per puff and Ventolin Evohaler $100 \mu \mathrm{g}$ per puff both containing hydrofluoroalkane. The prescription was made by the authorized physicians who have participated in the study upon invitation. Normal prescription practice was followed for prescribing the salbutamol metered dose preparation containing HFA after proper clinical evaluation.

\section{GENERAL PRACTITIONERS}

One hundred twenty general practitioners from different parts of Bangladesh were invited to participate in the safety assessment study. Out of them fourteen physicians from Dhaka and Chittagong, the two largest city of Bangladesh were responded to participate in the study. The letter of invitation described the rationale for replacing Azmasol a HFA containing salbutamol sulphate metered dose inhaler in place of Ventolin Evohaler and the number of patients to be enrolled.

\section{PATIENTS}

To generate a large population, patients were recruited in the ratio of one using a Ventolin Evohaler $100 \mu \mathrm{g}$ per puff to four using Azmasol inhaler $100 \mu \mathrm{g}$ per puff. They were considered for treatment with the hydrofluoroalkane inhalers only after the clinical decision had been made to start or modify salbutamol treatment diagnosed with asthma or other forms of diffuse reversible airways obstruction. Five patients in a territory were considered as a group. No ethnic patient was involved in the study.

\section{DATA COLLECTION}

Data were collected by the investigators from the patients' medical records from the hospitals and notes in the prescriptions during doctors' visits for the two month study period. The authenticity of data was ensured by conducting source data verification on one randomly selected patient in each group of five patients at each territory.

\section{STATISTICAL METHODS}

For data analysis SPSS was used. The sample size of 508 subjects is determined providing $80 \%$ statistical power to detect 0.15 difference of expected proportions between two treatment groups of patients at a significance level of 0.05 [10].

\section{RESULTS}

Altogether, 14 general practitioners (11.67\%) accepted the invitation to participate and 25 confirmed after they had received a detailed description of the study. Fourteen of these general practitioners, are from Dhaka and Chittagong, participated and recruited a total of 508 patients (408 of whom were using Azmasol inhaler and 100 Ven- 
Table 1. Demographic information of the patients participated in the study.

\begin{tabular}{|c|c|c|c|}
\hline \multirow[b]{2}{*}{ Variables } & \multicolumn{2}{|c|}{ Treatment Group } & \multirow[b]{2}{*}{ Total } \\
\hline & $\begin{array}{c}\text { Azmasol } \\
\text { Inhaler } \\
(\mathrm{n}=408) \\
\end{array}$ & $\begin{array}{c}\text { Ventolin } \\
\text { Evohaler } \\
(\mathrm{N}=100)\end{array}$ & \\
\hline Mean (SD) Age (yr) & $40.06(17.78)$ & $42.96(13.59)$ & \\
\hline \multicolumn{4}{|c|}{ Sex \% (No.) within Drug Used } \\
\hline Male & $62.7(256)$ & $64(64)$ & $63(320)$ \\
\hline Female & $37.3(156)$ & $36(36)$ & $37(188)$ \\
\hline Total & 80.9 (408) & $19.7(100)$ & \\
\hline
\end{tabular}

Data for some of the patients were not available. All the patients participate in this study were Bangladeshi. No ethnic patient was involved in the study group.

tolin Evohaler). The demographic data of the two patient groups were comparable in terms of age and sex (Table 1). The first patient was enrolled on 04 June 2010 and the study was completed on 26 September 2011.

\section{ADVERSE EVENTS}

General practitioners recorded adverse events in similar proportions of patients in each group (Table 2). The most commonly reported adverse affects were tremor (Asmasol 7.1\%, Ventolin 3.0\% with odd ratios 2.48 [0.74 - 8.31]); dizziness (Azmasol 6.4\%, Ventolin 2.0\% with odd ratios 3.36 [0.78 - 14.4]); headache (Azmasol 9.4\%, Ventolin $4.0 \%$ with odd ratios $2.45[0.86-7.11])$, heartburn (Azmasol 5.4\%, Ventolin 6.0\% with odd ratios 0.92 [0.36 - 2.33]) and palpitation (Azmasol 6.6\%, Ventolin $3.0 \%$ with odd ratios 2.29 [0.68 - 7.73]) (Table 3). General practitioners attributed more adverse events to Azmasol inhaler than to Ventolin Evohaler but were statistically indifferent. No deaths were attributable to the condition for which salbutamol had been prescribed.

\section{WITHDRAWAL FROM THE STUDY}

Total five patients using the Azmasol inhaler withdrew from the study. Only 1.23\% patients of Azmasol inhaler group withdrew for reasons unrelated to safety. These included intercurrent illness, lost to follow up, and taste. In the Azmasol group, two patients withdrew because they disliked the taste. Two patients using the Azmasol inhaler stopped taking study medication because of intercurrent illness and one due to lose of follow up. Other than these, most of the patients in both groups completed two months of treatment with the study medication.

\section{DISCUSSION}

A non-interventional, nonrandomized observational study was undertaken to document the post-marketing
Table 2. Comparative toxicities between two preparations among the patients in percentage those who experienced at least one adverse drug event.

\begin{tabular}{lccc}
\hline \multirow{2}{*}{ Parameters } & \multicolumn{2}{c}{ Drugs } & \\
\cline { 2 - 3 } & $\begin{array}{c}\text { Azmasol } \\
\text { Inhaler } \\
(\mathrm{n}=408)\end{array}$ & $\begin{array}{c}\text { Ventolin } \\
\text { Evohaler } \\
(\mathrm{N}=100)\end{array}$ & \\
\hline Immune system & $4.2(17)^{*}$ & $2.0(2)$ & 0.301 \\
Dizziness & $6.4(26)$ & $2.0(2)$ & 0.084 \\
Tremor & $7.1(29)$ & $3.0(3)$ & 0.129 \\
Headache & $9.4(38)$ & $4.0(4)$ & 0.820 \\
Nervousness & $3.9(16)$ & $2.0(2)$ & 0.348 \\
Diarrhoea & $0.7(03)$ & $0.0(0)$ & 0.388 \\
Nausea & $4.4(18)$ & $2.0(2)$ & 0.263 \\
Vomiting & $2.5(10)$ & $1.0(1)$ & 0.369 \\
Heartburn & $5.4(22)$ & $6.0(6)$ & 0.816 \\
Skin rash & $4.2(17)$ & $1.0(1)$ & 0.124 \\
Throat irritation & $2.0(08)$ & $4.0(4)$ & 0.231 \\
Bronchospasm & $0.7(03)$ & $0.0(0)$ & 0.389 \\
Palpitation & $6.6(27)$ & $3.0(3)$ & 0.143 \\
Fast heart rate & $2.5(10)$ & $2.0(2)$ & 0.788 \\
Elevated BP & $1.5(06)$ & $1.0(1)$ & 0.133 \\
Hypertension & $0.7(03)$ & $1.0(1)$ & 0.790 \\
\hline
\end{tabular}

*Figure in parenthesis indicates number of patients.

Table 3. Percentage of patients who had experienced most common adverse event, with odd ratios.

\begin{tabular}{cccc}
\hline \multirow{2}{*}{$\begin{array}{c}\text { Adverse } \\
\text { Events }\end{array}$} & \multicolumn{2}{c}{ Treatment Group [\% (No)] } & Odds Ratio \\
\cline { 2 - 3 } & $\begin{array}{c}\text { Azmasol } \\
\text { Inhaler } \\
(\mathrm{n}=408)\end{array}$ & $\begin{array}{c}\text { Ventolin } \\
\text { Evohaler } \\
(\mathrm{N}=100)\end{array}$ & $(95 \% \mathrm{CI})$ \\
\hline Tremor & $7.1(29)^{*}$ & $3.0(3)$ & $2.48[0.74-8.31]$ \\
Dizziness & $6.4(26)$ & $2.0(2)$ & $3.36[0.78-14.4]$ \\
Headache & $9.4(38)$ & $4.0(4)$ & $2.45[0.86-7.11]$ \\
Heartburn & $5.4(22)$ & $6.0(6)$ & $0.92[0.36-2.33]$ \\
Palpitation & $6.6(27)$ & $3.0(3)$ & $2.29[0.68-7.73]$ \\
\hline
\end{tabular}

*Figure in parenthesis indicates number of patients.

experience with Azamsol, a pressurized metered dose salbutamol inhaler using hydrofluoroalkane as the propellant. It aimed to evaluate the safety of a hydrofluoroalkane inhaler by comparing it with Ventolin Evohaler also containing hydrofluoroalkane, in patients prescribed with salbutamol in primary care. The study met the objectives of the safety assessment of marketed medicines [11].

The response rate of general practitioners to the invitation to participate in the study was very good (11.67\%). Conventional wisdom regarding large mail shots suggests that a response rate between $5 \%$ and $8 \%$ is usual [9].

The study highlighted several differences in study de- 
sign or conduct and outcome between a post-marketing surveillance and randomized controlled trials. We used the number of patients who had asthma or related respiratory disorders for which salbutamol had been prescribed as the primary outcome variable. This provided an objective indication of a severe exacerbation, likely to be documented fully in the patient's general practitioner records and to be less influenced by subjective perceptions of the effects of new medication. Other objective measures of asthma control are available, but incorporating these into the study would have meant imposing standardization of treatment upon general practitioners, which is contrary to the safety assessment of marketed medicines guidelines.

In this nonrandomized safety assessment the study was not blinded. Here the prescribers were concerned about the dosage form and medication, and the patients were well informed and adhered to their medication. In randomized clinical trials both the prescriber and patient are often blinded to the medication, but this is clearly not usual in clinical practice. The ability to assess the use of medicines under normal clinical conditions would have been lost when the study been blinded [9].

The proportion of patients reporting adverse events were similar in both groups, although it was confirmed the anticipated phenomenon that more events would be attributed to the Azmasol inhaler. The events most often considered by general practitioners to be related to the hydrofluoroalkane salbutamol formulation were those commonly associated with salbutamol treatment - tremor, dizziness, headache, heartburn, and palpitation (Tables 2 and 3). Hendeles et al. [12] observed the same effects on central nervous system, gastrointestinal, heart and others systems during safety and efficacy comparison between hydrofluoroalkane salbutamol approved by FDA and CFC containing salbutamol which was intended to replace. This is unlikely to be the result of an increased availability of salbutamol since clinical studies have shown that the adverse event profiles of Azmasol inhaler and Vento- lin Evohaler are the same [3-7].

\section{CONCLUSION}

The findings support the experience of safety assessment study of Azmasol, a metered dose salbutamol inhaler preparation containing hydrofluoroalkane as propellant, manufactured by BEXIMCO Pharmaceuticals Ltd., Dhaka, Bangladesh showing that it does not change the safety when compared with Ventolin Evohaler the standard hydrofluoroalkane containing salbutamol formulation. The study design was successful in terms of the number, rate, and spread of patients recruited, and shows that it is possible to fulfill the recommendations of the safety assessment of marketed medicines.

\section{ACKNOWLEDGEMENTS}

The authors express their gratitude to all the general practitioners who contributed patients and data to this study.

\section{REFERENCES}

[1] Association of the British Pharmaceutical Industry (1996) Guidelines for company sponsored safety assessment of marketed medicines (SAMM). In: ABPI Compendium of Data Sheets and Summaries of Product Characteristics. Datapharm Publications, London.

[2] Rawlins, M.D. and Jefferys, D.B. (1991) Study of United Kingdom product license applications containing new active substances, 1987-1989. British Medical Journal, 302, 223-225. doi:10.1136/bmj.302.6770.223

[3] Dockhorn, R., Vanden Burgt, J.A., Ekholm, B.P., Donnell, D. and Cullen, M.T. (1995) Clinical equivalence of a novel non-chlorofluorocarbon-containing salbutamol sulfate metered-dose inhaler and a conventional chlorofluorocarbon inhaler in patients with asthma. Journal of Allergy and Clinical Immunology, 96, 50-56. doi:10.1016/S0091-6749(95)70032-3

[4] Kleerup, E.C., Tashkin, D.P., Cline, A.C. and Ekholm, B.P. (1996) Cumulative dose-response study of non-CFC propellant HFA 134a salbutamol sulfate metered dose inhaler in patients with asthma. Chest, 109, 702-707. doi:10.1378/chest.109.3.702

[5] Tinkelman, D.G., Bleecker, E.R., Ramsdell, J., Ekholm, B.P., Klinger, N.M., Colice, G.L. and Slade, H.B. (1998) Proventil HFA and Ventolin have similar safety profiles during regular use. Chest, 113, 290-296. doi:10.1378/chest.113.2.290

[6] Bleecker, E.R., Tinkelman, D.G., Ramsdell, J., Ekholm, B.P., Klinger, N.M., Colice, G.L. and Slade, H.B. (1998) Proventil HFA provides bronchodilation comparable to Ventolin over 12 weeks of regular use in asthmatics. Chest, 113, 283-289. doi:10.1378/chest.113.2.283

[7] Craig-McFeely, P.M., Wilton, L.V., Soriano, J.B., Maier, W.C. and Shakir, S.A. (2003) Prospective observational cohort safety study to monitor the introduction of a nonCFC formulation of salbutamol with HFA134a in England. International Journal of Clinical Pharmacology, Therapy, \& Toxicology, 41, 67-76.

[8] Report of the Auditor General of Canada to the House of Commons (2011) Regulating pharmaceutical drugsHealth Canada. Minister of Public Works and Government Services, 26.

[9] Ayres, J.G., Frost, C.D., Holmes, W.F., Williams, D.R.R. and Ward, S.M. (1998) Postmarketing surveillance study of a non-chlorofluorocarbon inhaler according to the safety assessment of marketed medicines guidelines. British Medical Journal, 317, 926-930. doi: $10.1136 / \mathrm{bmj} .317 .7163 .926$

[10] http://www.stattools.net/SSize2props_Pgm.php

[11] European Agency for the Evaluation of Medicinal Products (1995) Guideline for postmarketing surveillance studies for metered dose inhalers with new propellants. 
EAEMP, London.

[12] Hendeles, L., Colice, G.L. and Meyer, R.J. (2007) Withdrawal of albuterol inhalers containing chlorofluorocar- bon propellants. New England Journal of Medicine, 356, 1344-1351. doi:10.1056/NEJMra050380 